\title{
Green Lewis acid catalysis in organic synthesis*
}

\author{
Shū Kobayashi† and Kei Manabe \\ Graduate School of Pharmaceutical Sciences, The University of Tokyo, Hongo, \\ Bunkyo-ku, Tokyo 113-0033, Japan
}

\begin{abstract}
New types of Lewis acids as water-stable catalysts have been developed. Metal salts such as rare earth metal triflates can be used in carbon-carbon bond-forming reactions in aqueous media. These salts can be recovered after the reactions and reused. Furthermore, Lewis acid-surfactant-combined catalysts, which can be used for reactions in water without using any organic solvents, have been also developed. Finally, Lewis acid catalysis in supercritical carbon dioxide has been successfully performed. These investigations will contribute to development of environmentally friendly Lewis acid catalysis.
\end{abstract}

\section{INTRODUCTION}

Lewis acid catalysis has been of great interest in organic synthesis [1]. While various kinds of Lewis acid-promoted reactions have been developed, and many have been applied in industry, these reactions must be generally carried out under strictly anhydrous conditions. The presence of even a small amount of water stops the reaction, because most Lewis acids immediately react with water rather than the substrates and decompose, and this has restricted the use of Lewis acids in organic synthesis. From a viewpoint of green chemistry, however, it is desirable to use water instead of organic solvents as a reaction solvent, since water is a safe, harmless, and environmentally benign solvent [2]. In the course of our investigations to develop new synthetic methods, we have found that rare earth metal triflates $\left[\mathrm{Sc}(\mathrm{OTf})_{3}, \mathrm{Yb}(\mathrm{OTf})_{3}\right.$, etc.] and some other metal salts can be used as water-stable Lewis acids in watercontaining solvents. Furthermore, a new type of a Lewis acid, a Lewis acid-surfactant-combined catalyst, has been developed for the Lewis acid-catalyzed reactions in water without using any organic solvents. In this article, our research work on use of the Lewis acid catalysts in carbon-carbon bond-forming reactions in aqueous solvents is overviewed [3]. As an extension of this work, a possibility of Lewis acid catalysis in supercritical carbon dioxide is also discussed.

\section{WATER-STABLE LEWIS ACIDS}

The titanium tetrachloride $\left(\mathrm{TiCl}_{4}\right)$-mediated aldol reaction of silyl enol ethers with aldehydes was first reported in 1973 [4]. The reaction (Mukaiyama aldol reaction) is notably distinguished from the conventional aldol reactions carried out under basic conditions; it proceeds in a highly regioselective manner to afford crossed-aldol adducts in high yields [5]. Since this pioneering effort, several efficient activators have been developed to realize high yields and selectivities, and now the reaction is considered to be one of the most important carbon-carbon bond-forming reactions in organic synthesis [6]. However, these reactions are usually carried out under strictly anhydrous conditions due to the water-labile nature of the Lewis acids.

A disadvantage of using anhydrous conditions is that substrates which contain water of crystallization or are available as water solutions cannot be used directly. On the other hand, we found that lanthanide triflates $\left[\mathrm{Ln}(\mathrm{OTf})_{3}\right]$ functioned as water-stable Lewis acid catalysts. Lanthanide compounds were expected to act as strong Lewis acids because of their hard character and to have strong affinity

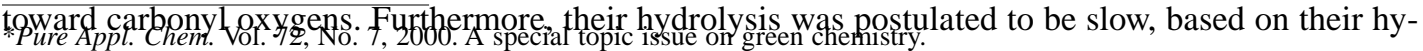
Corresponding author: E-mail: skobayas@mol.f.u-tokyo.ac.jp 
dration energies and hydrolysis constants [7]. In fact, while most metal triflates are prepared under strictly anhydrous conditions, $\operatorname{Ln}(\mathrm{OTf})_{3}$ are reported to be prepared in aqueous solution [8]. The usefulness of these Lewis acids was first demonstrated in the hydroxymethylation of silyl enol ethers by using commercial formaldehyde aqueous solution [9]. Among the $\operatorname{Ln}(\mathrm{OTf})_{3}$ tested for the aldol reaction, $\mathrm{Yb}(\mathrm{OTf})_{3}$ was found to be the most effective catalyst (Eq. 1). It is noted that only a catalytic amount of $\mathrm{Yb}(\mathrm{OTf})_{3}$ was required to complete the reaction.

$\mathrm{Ln}(\mathrm{OTf})_{3}$, especially $\mathrm{Yb}(\mathrm{OTf})_{3}$, also activate aldehydes other than formaldehyde in aldol reactions with silyl enol ethers in aqueous solvents [10]. One feature in the present reactions is that water-

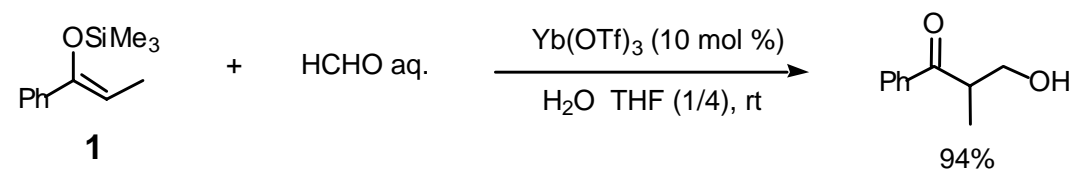

soluble aldehydes, for instance, acetaldehyde, acrolein, and chloroacetaldehyde can be used directly for the reactions with silyl enol ethers to afford the corresponding crossed-aldol adducts in high yields. Another striking feature of $\operatorname{Ln}(\mathrm{OTf})_{3}$ is that it is very easy to recover them from the reaction mixture. $\mathrm{Ln}(\mathrm{OTf})_{3}$ are more soluble in water than in organic solvents such as dichloromethane. Almost $100 \%$ of $\operatorname{Ln}(\mathrm{OTf})_{3}$ was quite easily recovered from the aqueous layer after the reaction was completed, and it could be reused. The reactions are usually quenched with water and the products are extracted with an organic solvent. The catalyst is in the aqueous layer, and only removal of water gives the catalyst which can be used in the next reaction (Scheme 1). It is noteworthy that $\mathrm{Ln}(\mathrm{OTf})_{3}$ are expected to solve some severe environmental problems induced by Lewis acid-promoted reactions in industrial chemistry [11].

In the present $\mathrm{Ln}(\mathrm{OTf})_{3}$-catalyzed aldol reactions in aqueous media, the amount of water strongly influenced the yields of the aldol adducts. The effects of the amount of water on the yield in the model reaction of benzaldehyde with silyl enol ether 2 in the presence of 10 mol \% Yb(OTf) 3 in THF were investigated (Eq. 2). The best yields were obtained when the ratios of water in THF were 10-20\%. When the amount of water increased, the yield began to decrease. The reaction system became two phases when the amount of water increased, and the yield decreased. Only $18 \%$ of the product was isolated in $100 \%$ water solution. On the other hand, when water was not added, or 1-5 eq. of water were

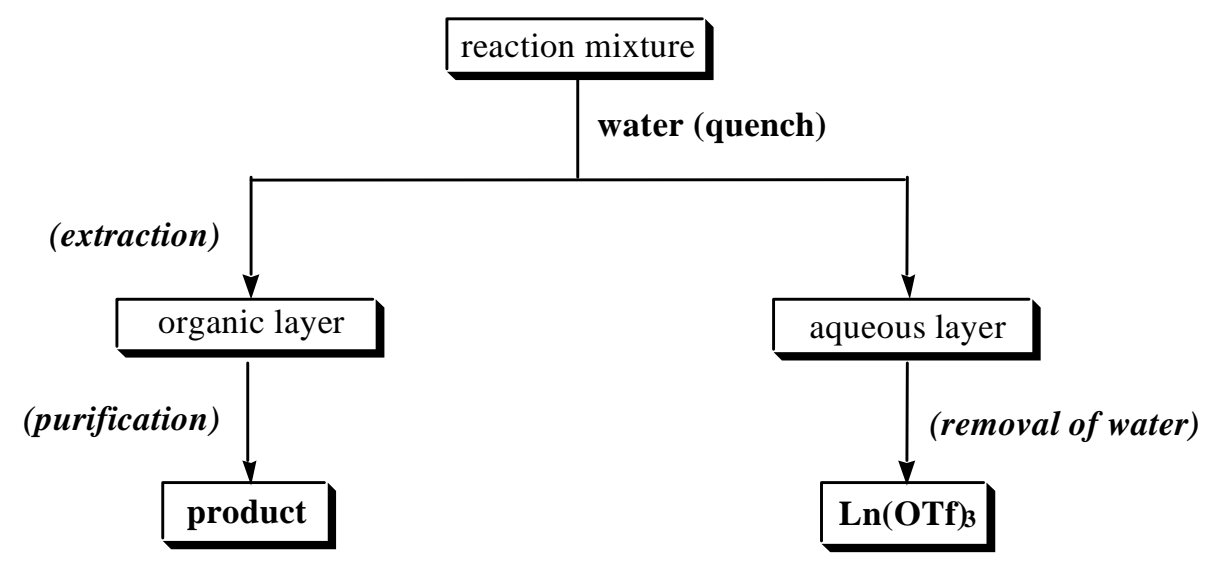

Scheme 1 Recovery of the catalyst. 

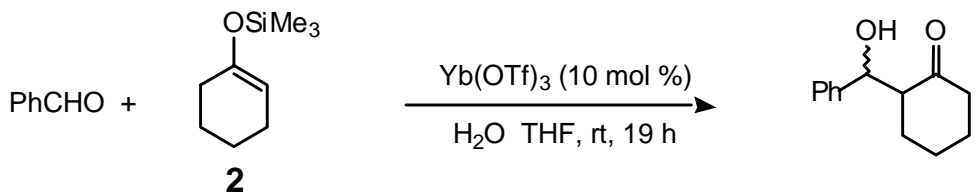

added to $\mathrm{Yb}(\mathrm{OTf})_{3}$, the yield of the desired aldol adduct was also low (ca. 10\% yield). The yield improved as water was increased to 6-10 eq., and when more than 50 eq. of water were added, the yield improved to more than $80 \%$. These results indicate that water acts as not only a co-solvent but also a kind of an activator in the reaction.

Scandium triflate $\left(\mathrm{Sc}(\mathrm{OTf})_{3}\right)$ was also found to be an effective catalyst in aldol reactions in aqueous media. For many cases, $\mathrm{Sc}(\mathrm{OTf})_{3}$ was more active than $\mathrm{Yb}(\mathrm{OTf})_{3}$ and $\mathrm{Y}(\mathrm{OTf})_{3}$ as expected from the smaller ionic radius of $\mathrm{Sc}(\mathrm{III})$.

In order to search other Lewis acids stable in aqueous solvents, group 1-15 metal chlorides were screened [12]. As a model, the reaction of benzaldehyde with silyl enol ether $\mathbf{1}$ in $\mathrm{H}_{2} \mathrm{O}-\mathrm{THF}$ was selected. In the screening, the chloride salts of $\mathrm{Fe}(\mathrm{II}), \mathrm{Cu}(\mathrm{II}), \mathrm{Zn}(\mathrm{II}), \mathrm{Cd}(\mathrm{II}), \mathrm{In}(\mathrm{III})$, and $\mathrm{Pb}(\mathrm{II})$, as well as the rare earth metals ( $\mathrm{Sc}(\mathrm{III}), \mathrm{Y}(\mathrm{III}), \mathrm{Ln}(\mathrm{III})$ ) gave promising yields. When the chloride salts of $\mathrm{B}(\mathrm{III})$, $\mathrm{Si}(\mathrm{IV}), \mathrm{P}(\mathrm{III}), \mathrm{P}(\mathrm{V}), \mathrm{Ti}(\mathrm{IV}), \mathrm{V}(\mathrm{III}), \mathrm{Ge}(\mathrm{IV}), \mathrm{Zr}(\mathrm{IV}), \mathrm{Nb}(\mathrm{V}), \mathrm{Mo}(\mathrm{V}), \mathrm{Sn}(\mathrm{IV}), \mathrm{Sb}(\mathrm{V}), \mathrm{Hf}(\mathrm{IV}), \mathrm{Ta}(\mathrm{V}), \mathrm{W}(\mathrm{VI})$, $\operatorname{Re}(\mathrm{V})$, and $\mathrm{Tl}(\mathrm{III})$ were used, decomposition of the silyl enol ether occurred rapidly, and no aldol adduct was obtained. This is because hydrolysis of such metal chlorides is very fast, and the silyl enol ether was protonated then hydrolyzed to afford the corresponding ketone. On the other hand, no product or only a trace amount of the product was detected using the metal chloride salts of $\mathrm{Li}(\mathrm{I}), \mathrm{Na}(\mathrm{I}), \mathrm{Mg}(\mathrm{II})$, $\mathrm{Al}(\mathrm{III}), \mathrm{K}(\mathrm{I}), \mathrm{Ca}$ (II), $\mathrm{Cr}$ (III), Mn(II), $\mathrm{Co}$ (II), Ni(II), Ga(III), Ru(III), Rh(III), Pd(II), $\mathrm{Ag}$ (I), $\mathrm{Ba}$ (II), Os(III), $\mathrm{Ir}(\mathrm{III}), \mathrm{Pt}(\mathrm{II}), \mathrm{Au}(\mathrm{I}), \mathrm{Hg}(\mathrm{II})$, and $\mathrm{Bi}(\mathrm{III})$. Some of these salts are stable in water, but have low catalytic ability. We noticed a correlation between their catalytic activity in aqueous media and hydrolysis constants $\left(K_{\mathrm{h}}\right)$ and exchange rate constants for substitution of inner-sphere water ligands (water exchange rate constant (WERC)) [7]. The metal compounds which were active in the aldol reaction have $\mathrm{p} K_{\mathrm{h}}$ values from 4.3 to 10.08 and WERC greater than $3.2 \times 10^{6} \mathrm{M}^{-1} \mathrm{~s}^{-1}$. Cations are generally difficult to hydrolyze when their $\mathrm{p} K_{\mathrm{h}}$ values are large. In the case that $\mathrm{p} K \mathrm{~h}$ values are less than 4.3 , cations are easy to hydrolyze, and oxonium ions are formed. Under these conditions, silyl enol ethers decompose rapidly. On the other hand, in the case that $\mathrm{p} K_{\mathrm{h}}$ values are more than 10.08 , the Lewis acidity of the cations are too low to catalyze the aldol reaction. WERC values should be large for effective Lewis acids in aqueous media, because large WERC values secure fast exchange between hydrated water molecules and an aldehyde which must coordinate to the metal cation to be activated.

Judging from these findings, the mechanism of Lewis acid catalysis in water (for example, aldol reactions of aldehydes with silyl enol ethers) can be assumed to be as follows. When metal compounds are added to water, the metals dissociate and hydration occurs immediately. At this stage, the intramolecular and intermolecular exchange reactions of water molecules frequently occur. If an aldehyde exists in the system, there is a chance for it to coordinate to the metal cations instead of the water molecules, and the aldehyde is then activated. A silyl enol ether attacks this activated aldehyde to produce the aldol adduct. According to this mechanism, it is expected that many Lewis acid-catalyzed reactions should be successful in water solution. Although the precise activity as Lewis acids in aqueous media cannot be quantitatively predicted by $\mathrm{p} K_{\mathrm{h}}$ and WERC values, these results have shown the possibility of using several promising metal compounds as Lewis acid catalysts in water.

\section{LEWIS ACIDS WITH SURFACTANT MOLECULES}

While the Lewis acid-catalyzed aldol reactions in aqueous solvents described above were smoothly catalyzed by several metal salts, a certain amount of organic solvent, such as THF, had to be still combined with water to promote the reactions efficiently. To avoid the use of the organic solvents, we have developed a new reaction system in which metal triflates catalyze aldol reactions in water without using any organic solvents with the aid of a small amount of a surfactant such as sodium dodecyl sulfate (SDS).

(C) 2000 IUPAC, Pure and Applied Chemistry 72, 1373-1380 


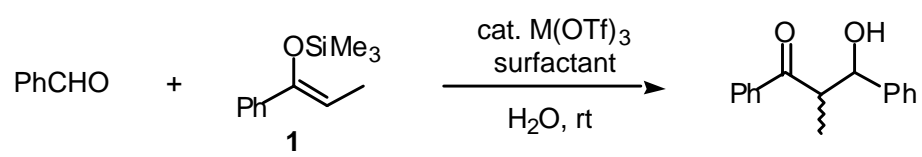

Table 1. Effect of $M(O T f)_{3}$ and Surfactants

\begin{tabular}{llcc}
\hline $\mathrm{M}(\mathrm{OTf})_{3} / \mathrm{mol} \%$ & Surfactant $/ \mathrm{mol} \%$ & Time $/ \mathrm{h}$ & Yield $/ \%$ \\
\hline $\mathrm{Yb}(\mathrm{OTf})_{3} / 20$ & - & 48 & 17 \\
$\mathrm{Yb}(\mathrm{OTf})_{3} / 20$ & $\mathrm{SDS} / 20$ & 48 & 50 \\
$\mathrm{Sc}(\mathrm{OTf})_{3} / 10$ & $\mathrm{SDS} / 20$ & 4 & 88 \\
$\mathrm{Sc}(\mathrm{OTf})_{3} / 10$ & TritonX-100/20 & 60 & 89 \\
$\mathrm{Sc}(\mathrm{OTf})_{3} / 10$ & $\mathrm{CTAB} / 20$ & 4 & trace \\
\hline
\end{tabular}

The surfactant-aided Lewis acid catalysis was first found in the model reaction shown in Table 1 [13]. While the reaction proceeded sluggishly in the presence of $20 \mathrm{~mol} \% \mathrm{Yb}(\mathrm{OTf})_{3}$ in water, remarkable enhancement of the reactivity was observed when the reaction was carried out in the presence of 20 $\mathrm{mol} \% \mathrm{Yb}(\mathrm{OTf})_{3}$ in an aqueous solution of $\operatorname{SDS}(20 \mathrm{~mol} \%, 35 \mathrm{mM})$, and the corresponding aldol adduct was obtained in $50 \%$ yield. The yield was improved when $\mathrm{Sc}(\mathrm{OTf})_{3}$ was used as a Lewis acid catalyst. It was found that the surfactants influenced the yield, and that TritonX-100, a neutral surfactant, was effective in the aldol reaction (but required long reaction time), while only a trace amount of the adduct was detected when using a representative cationic surfactant, cetyltrimethylammonium bromide (CTAB).

A surprising feature of the $\mathrm{Sc}(\mathrm{OTf})_{3}-\mathrm{SDS}$ system is that ketene silyl acetal $\mathbf{3}$, which is known to be hydrolyzed very easily even in the presence of a small amount of water, reacted with an aldehyde to afford the corresponding aldol adduct in a high yield (Eq. 3).

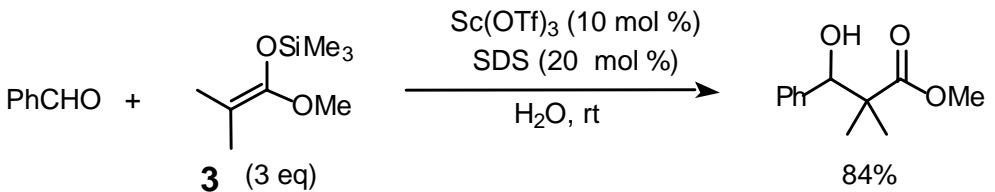

This system was successfully applied to three-component Mannich-type reactions of aldehydes, amines, and silyl enolates in water (Eq. 4) [14]. It is noteworthy in these reactions that the intermediate imines were formed in situ from aldehydes and amines even in the presence of water as a solvent.

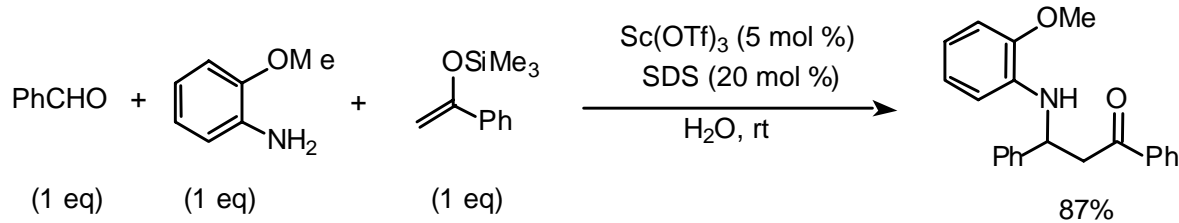

With these results in hand, we have next introduced new types of Lewis acids, scandium tris(dodecyl sulfate) (4a) and scandium trisdodecanesulfonate (5a) (Chart 1) [15]. These "Lewis acid-surfactantcombined catalysts (LASCs)" were found to form stable colloidal dispersions with organic substrates in water and efficiently catalyze aldol reactions of aldehydes with very water-labile silyl enol ethers.

To investigate this LASC system in detail, we have synthesized dodecyl sulfate and dodecanesulfonate salts with various metal cations (Chart 1) and studied the effects of the metal cations 


$\begin{array}{lll}M\left(\mathrm{O}_{3} \mathrm{SO} \mathrm{C}_{12} \mathrm{H}_{25}\right)_{n} & M\left(\mathrm{O}_{3} \mathrm{~S} \mathrm{C}_{12} \mathrm{H}_{25}\right)_{n} & \\ & & \\ \text { 4a: } M=S c, n=3 & \text { 5a: } M=S c, n=3 & \text { 5e: } M=C u, n=2 \\ \text { 4b: } M=C u, n=2 & \text { 5b: } M=Y b, n=3 & \text { 5f: } M=Z n, n=2 \\ & \text { 5c: } M=M n, n=2 & \text { 5g: } M=N a, n=1 \\ & \text { 5d: } M=C o, n=2 & \text { 5h: } M=A g, n=1\end{array}$

\section{Chart 1.}

on catalytic ability for aldol reactions in water [16]. The catalysts were used in the aldol reactions of benzaldehyde (1 eq) with thioketene silyl acetal 6 (1.5 eq) in water (Eq. 5). Remarkable effects of the metal cations on catalytic activity can be observed from the reaction profiles (Fig. 1). The order of catalytic activity at the initial stage of the reaction is as follows: $\mathrm{Cu}(\mathbf{5 e})>\mathrm{Zn}(\mathbf{5 f}), \mathrm{Ag}(\mathbf{5 h})>\mathrm{Sc}(\mathbf{5 a}), \mathrm{Yb}$ $(\mathbf{5 b})>\mathrm{Na}(\mathbf{5 g})>\mathrm{Mn}(\mathbf{5} \mathbf{c}), \mathrm{Co}(\mathbf{5 d})$. The Cu salt $(\mathbf{5 e})$ has the highest ability to catalyze the aldol reaction among the catalysts used. However, the yield of $\mathbf{7}$ did not exceed $70 \%$, because $\mathbf{5 e}$ accelerated not only the aldol reaction but also hydrolysis of thioketene silyl acetal $\mathbf{6}$. The same trend was observed for the $\mathrm{Zn}$ and $\mathrm{Ag}$ salts $(\mathbf{5 f}, \mathbf{5 h})$. On the other hand, the $\mathrm{Sc}$ and $\mathrm{Yb}$ salts $(\mathbf{5 a}, \mathbf{5 b})$ afforded the aldol product (7) in $>90 \%$ final yields, although the catalytic activities of $\mathbf{5} \mathbf{a}$ and $\mathbf{5 b}$ at the initial stage of the reaction were slightly lower than those of $\mathbf{5 e}, \mathbf{5 f}$, and $\mathbf{5 h}$. It should be noted that, in the dispersion system derived from $\mathbf{5 a}$ and $\mathbf{5 b}$, the hydrolysis of thioketene silyl acetal $\mathbf{6}$ was attenuated. Especially in the case of $\mathbf{5 a}$, a small

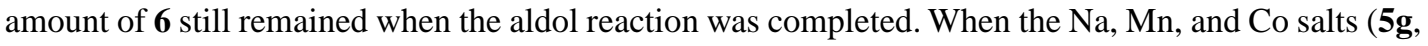
$\mathbf{5 c}, \mathbf{5 d}$ ) were used as catalysts, the aldol reactions proceeded very slowly, and the hydrolysis of $\mathbf{6}$ competed with the desired reaction, resulting in low yields of 7 .
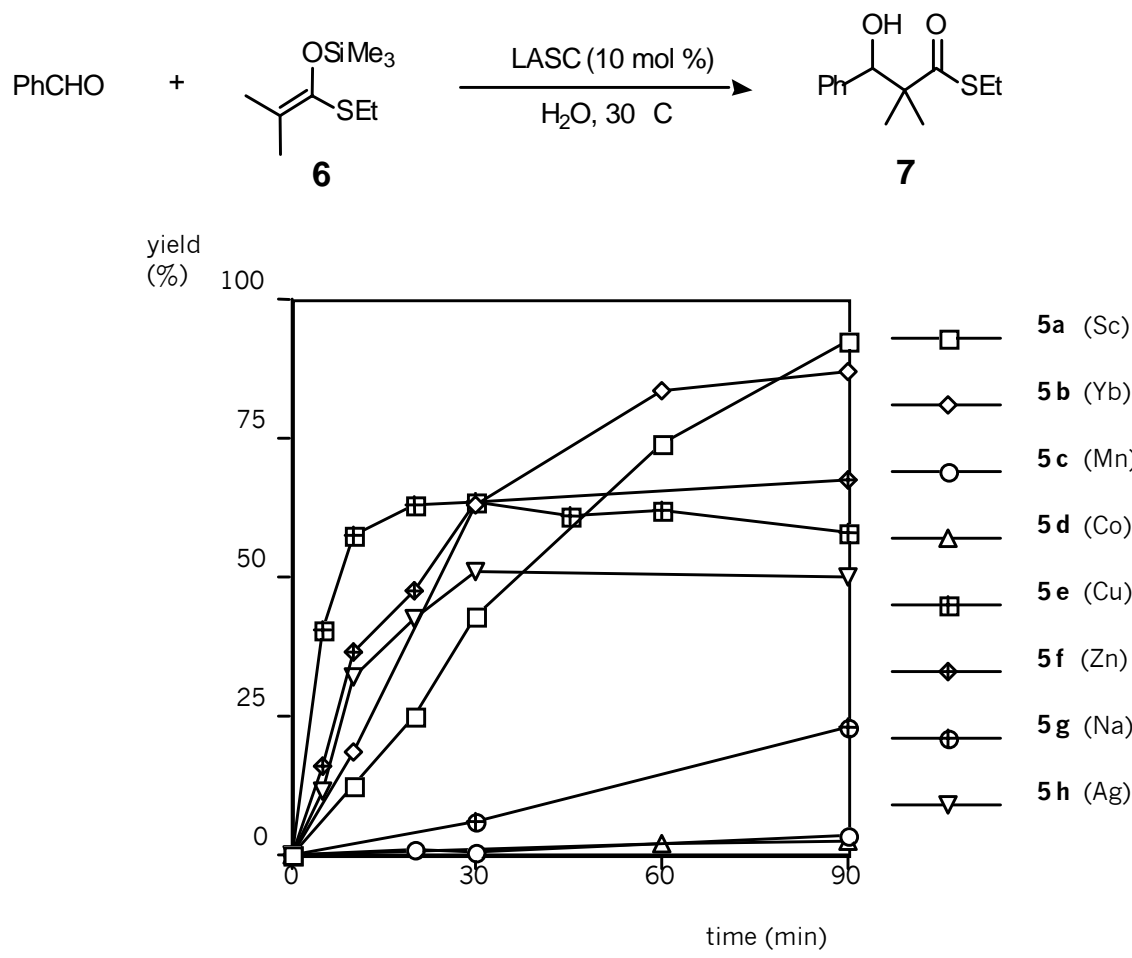

Fig. 1 Plot of yield versus time for the aldol reactions in the presence of the dodecanesulfonate salts.

(C) 2000 IUPAC, Pure and Applied Chemistry 72, 1373-1380 
During our investigations on the reactions mediated by LASCs, we have found that addition of a small amount of a Brønsted acid dramatically increases the reactivity of the aldol reaction (Eq. 6) [17]. This cooperative effect of a LASC and an added Brønsted acid was also observed in the allylation reaction of benzaldehyde with tetraallyltin in water [17b]. Although, from a mechanistic point of view, little is known about the real catalytic function of scandium and proton, this cooperative effect of a Lewis acid and a Brønsted acid will provide a new methodology for efficient catalytic systems in synthetic chemistry.

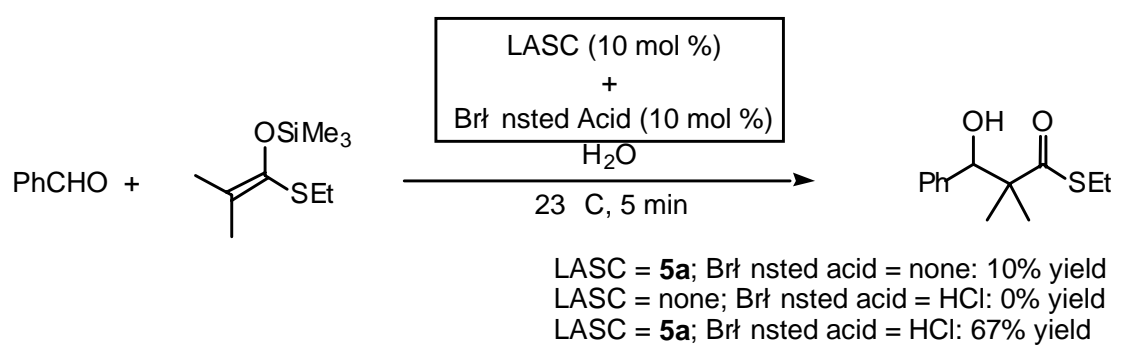

This LASC/Brønsted acid system has further extended to a catalytic asymmetric aldol reaction in water [18]. An example is shown in Eq. 7. A combination of $\mathbf{4 b}$ and a chiral bis(oxazoline) ligand to afford the desired products in a low yield (23\%) with a modest enantiomeric excess (58\% ee). However, addition of a Brønsted acid, especially a carboxylic acid such as lauric acid, improved both the yield and the enantioselectivity. This is the first example of Lewis acid-catalyzed asymmetric aldol reactions in

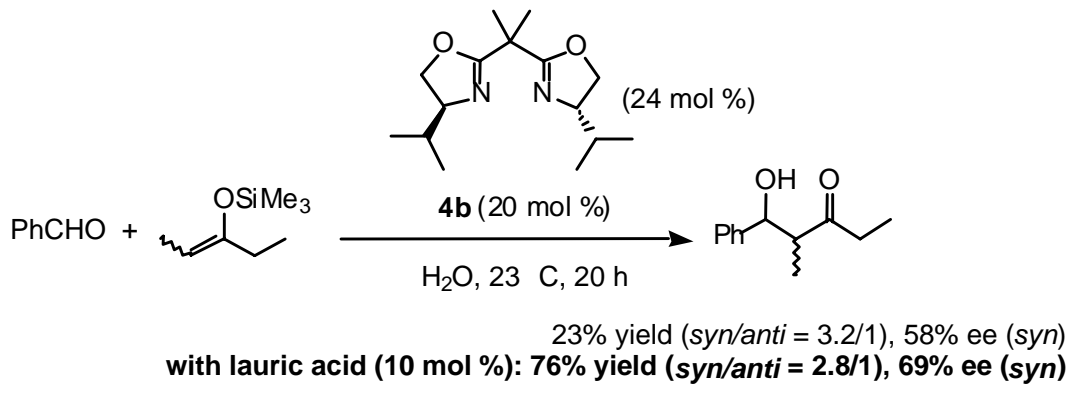

water without using organic solvents. Although the yields and the selectivities are still not yet optimized, it is noted that this enantioselectivity has been attained at ambient temperature in water.

\section{LEWIS ACID CATALYSIS IN SUPERCRITICAL CARBON DIOXIDE}

Although water works as a Lewis base to coordinate to the Lewis acid in the above reactions, the coordination occurs under equilibrium conditions and Lewis acid catalysis has been performed efficiently in such media. Similarly, it was expected that such Lewis acids would work well in supercritical carbon dioxide $\left(\mathrm{scCO}_{2}\right)$, which has also been regarded as a desirable substitute for some toxic organic solvents to accomplish benign chemical reactions [19]. Quite recently, Diels-Alder reactions of carbonyl dienophiles with dienes (Eq. 8) and aza Diels-Alder reactions of imines with a diene (Eq. 9) were found to be successfully carried out using scandium tris(heptadecafluorooctanesulfonate) $\left(\mathrm{Sc}\left(\mathrm{O}_{3} \mathrm{SC}_{8} \mathrm{~F}_{17}\right)_{3}\right)$ as a Lewis acid catalyst in supercritical carbon dioxide $\left(\mathrm{scCO}_{2}\right)$ [20]. It was revealed that the length of perfluorocarbon chains of the scandium catalyst was an essential factor for the catalytic activity in $\mathrm{scCO}_{2}$. 


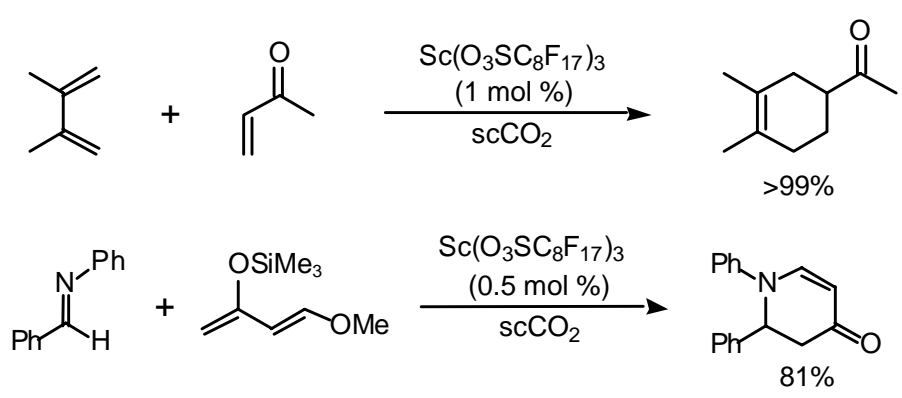

\section{CONCLUSION}

Various metal salts such as rare earth metal triflates can function as recoverable and reusable Lewis acids in aqueous media. Furthermore, LASCs promoted reactions in water without any organic solvents. Lewis acid catalysis is also successfully carried out in $\mathrm{scCO}_{2}$. The Lewis acids described in this article are expected to be new types of catalysts providing some solutions for environmental problems. The investigations on reactions in aqueous media or $\mathrm{scCO}_{2}$ will lead to the full understanding of the roles of water or $\mathrm{scCO}_{2}$, and also contribute to development of "greener" reactions.

\section{ACKNOWLEDGMENTS}

Our work was partially supported by CREST, Japan Science and Technology Corporation (JST) and a Grant-in-Aid for Scientific Research from the Ministry of Education, Science, Sports, and Culture, Japan.

\section{REFERENCES}

1. D. Schinzer (Ed.). Selectivities in Lewis Acid Promoted Reactions, Kluwer Academic Publishers, Dordrecht (1989).

2. (a) P. A. Grieco (Ed.). Organic Synthesis in Water, Blacky Academic and Professional, London (1998). (b) C.-J. Li. Chem. Rev. 93, 2023 (1993).

3. (a) S. Kobayashi. Lanthanides: Chemistry and Use in Organic Synthesis, p. 63, Springer, Heidelberg (1999). (b) S. Kobayashi. Eur. J. Org. Chem. 15 (1999). (c) S. Kobayashi. Synlett. 689 (1994).

4. (a) T. Mukaiyama, K. Narasaka, T. Banno. Chem Lett. 1011 (1973). (b) T. Mukaiyama, K. Banno, K. Narasaka. J. Am. Chem. Soc. 96, 7503 (1974).

5. T. Mukaiyama. Org. React. 28, 203 (1982).

6. T.-H. Chan. In Comprehensive Organic Synthesis, Vol. 2, Chapter 2.3, B. M. Trost (Ed.), Pergamon Press, New York (1991).

7. (a) C. F. Baes, Jr. and R. E. Mesmer. The Hydrolysis of Cations, p. 129, Wiley, New York (1976). (b) K. B. Yatsimirksii and V. P. Vasil'ev. Instability Constants of Complex Compounds, Pergamon, New York (1960). (c) A. E. Martell (Ed.). Coordination Chemistry, Vol. 2, ACS Monograph 168, American Chemical Society,Washington, DC (1978).

8. (a) K. F. Thom, U.S. Patent 3615169 (1971); CA 1972, 76, 5436a. (b) J. H. Forsberg, V. T. Spaziano, T. M. Balasubramanian, G. K. Liu, S. A. Kinsley, C. A. Duckworth, J. J. Poteruca, P. S. Brown, J. L. Miller. J. Org. Chem. 52, 1017 (1987).

9. S. Kobayashi. Chem. Lett. 2187 (1991).

10. S. Kobayashi and I. Hachiya. Tetrahedron Lett. 1625 (1992).

(C) 2000 IUPAC, Pure and Applied Chemistry 72, 1373-1380 
11. J. Haggin. Chem. Eng. News, Apr 18, 22 (1994).

12. S. Kobayashi, S. Nagayama, T. Busujima. J. Am. Chem. Soc. 120, 8287 (1998).

13. S. Kobayashi, T. Wakabayashi, S. Nagayama, H. Oyamada. Tetrahedron Lett. 38, 4559 (1997).

14. S. Kobayashi, T. Busujima, S. Nagayama. Synlett. 545 (1999).

15. S. Kobayashi and T. Wakabayashi. Tetrahedron Lett. 39, 5389 (1998).

16. (a) K. Manabe and S. Kobayashi. Synlett 1999, 547. (b) K. Manabe, Y. Mori, S. Kobayashi. Tetrahedron 55, 11203 (1999).

17. (a) K. Manabe and S. Kobayashi. Tetrahedron Lett. 40, 3773 (1999). (b) K. Manabe, Y. Mori, S Nagayama, S. Kobayashi. Inorg. Chim. Acta 296, 158 (1999).

18. S. Kobayashi, Y. Mori, S. Nagayama, K. Manabe. Green Chemistry 1, 175 (1999).

19. P. G. Jessop, T. Ikariya, R. Noyori. Chem. Rev. 99, 475 (1999).

20. J. Matsuo, T. Tsuchiya, K. Odashima, S. Kobayashi. Chem. Lett. 178 (2000). 